\title{
MECHANICS ANALYSIS OF 3D BRAIDED COMPOSITES BASED ON THE HELIX GEOMETRY MODEL
}

\author{
Tao Zeng, Lili Jiang \\ Department of Engineering Mechanics, Harbin University of Science and Technology, \\ 150080 Harbin, P. R. China, taozeng@sohu.com
}

\begin{abstract}
The helix geometry model of 3D braided composites has been presented, which truly reflects the braided manner and coincides with the actual configuration of the braided composites. The longitudinal tensile stress-strain relationships and the strength of 3D braided composites under the tension loading have been predicted by a finite multiphase element method (FMEM) based on the helix geometry model. Comparisons are conducted for those from the present model and experiment. The results obtained from the present model are supported by the experimental data. The numerical results show that the braiding angle has a significant influence on the strength of $3 \mathrm{D}$ braided composites.
\end{abstract}

Keywords- Helix Geometry Model, 3D Braided Composites, Mechanical Properties, Strength

\section{INTRODUCTION}

The utilization of 3D braided composites has developed rapidly in the past years for its excellent mechanical properties, such as high specific strength, high specific stiffness, high through-thickness strength and impact resistance, etc. Therefore, 3D braided composites have been used widely in the aerospace, automobile, marine and biomedical, etc. The 3D braided composites can be regarded as an assemblage of representative volume element (RVE) [1,2] that captured the major features of the underlying microstructure and composition in the material. Ma, Yang and Byun [3-5] first studied the effective elastic properties of 3D braided composites by using 'Fiber interlock model', 'Fiber inclination model' and 'fabric geometric model', respectively. Huang, Li and Sun [6-8] analyzed the strength of 3D braided composites based on corresponding geometry models, respectively. Wang and Wang [9] reported a mixed volume averaging technique to predict the mechanical behavior of three dimensional braided composites. Witcomb and Woo [10] gave the stress distribution of woven composites using the local finite element method. Zeng [11-13] predicted the stiffness, strength and nonlinear of 3D braided composites under the 3D mechanical loading based on the traditional topological model. $\mathrm{Gu}$ and $\mathrm{Yu}[14,15]$ studied the uniaxial strength of 3D braided composites, and showed the tensile curve within the whole strain range and the curves of the strength along with the braiding angle, respectively. Surya Kalidindi and Eric [16] developed a helix fiber cell to conduct the numerical evaluation of the 3D braided composite using commercial FE package I-DEAS. The interweave relationship and space shape within the yarns were embodied in the model. However, the yarn and matrix components of the RVE were modeled discretely in meshing and 
this is quite time-consuming. The main purpose of the present work is to predict the longitudinal tensile stress-strain relationships and the strength of 3D braided composites under the tension loading by FMEM based on the helix geometry model. The influence of the braiding angle on the strength of 3D braided composites is discussed.

\section{FORMATION OF THE PROBLEM}

\subsection{Unit-cell geometry}

A schema for the helix geometry model of 3D braided composites is shown in Fig.1, where a local coordinate system $\left(x^{\prime} y^{\prime} z\right)$ and a global coordinate system (xyz) have been employed. The yarns in the helix geometry model have been curved to avoid the collision of yarns each other at the center of the unit-cell.

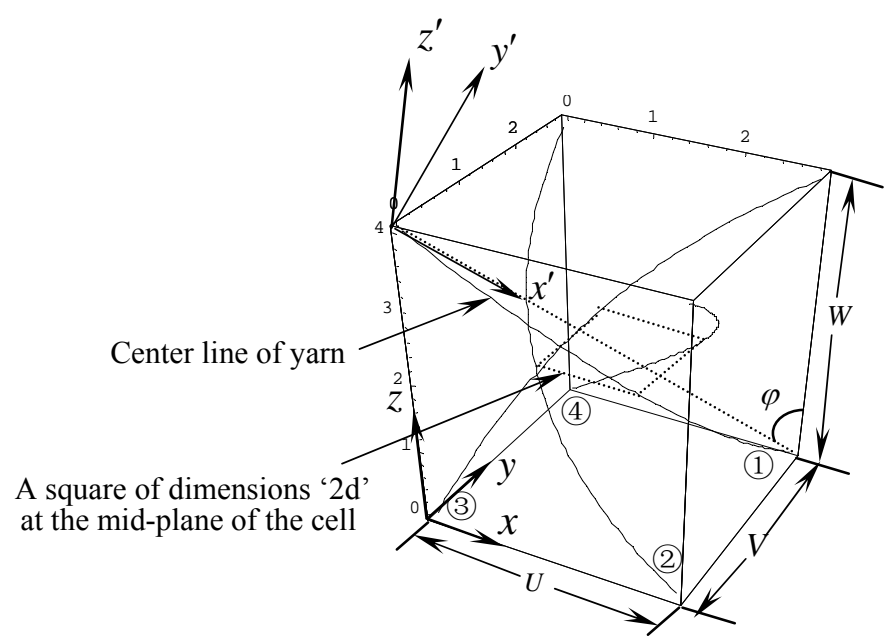

(a)

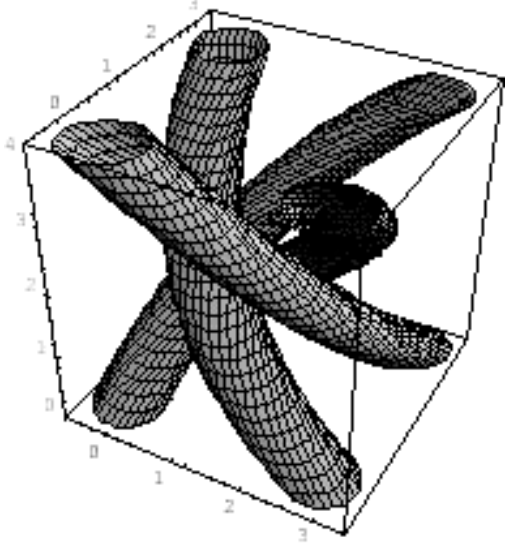

(b)

Fig.1 A representative cell of 3D braided composites for helix geometry model

It was assumed that dimensions of the unit-cell are $\mathrm{U}, \mathrm{V}$ and $\mathrm{W}$ in the $\mathrm{x}, \mathrm{y}$ and $\mathrm{z}$ directions, respectively. The yarn diameter is represented by $d$, and $\varphi$ is the angle between the diagonal line of the unit-cell and the braid axis. The yarns were supposed to curve helix columns in this study. The center lines of the yarns are curves and the crosssection of each yarn in XY plane is an ellipse. In order to describe the spatial location of the yarns and the micro-structural details of the unit-cell, the curvature and cross-section parameters of each yarn should be determined. The center line of each yarn in the unitcell is established by a parabola defined by the two yarn end points (located on the top and bottom surface of the cell) and the midpoint of the yarn (located on a plane parallel to and midway between the top and bottom surfaces), as shown in Fig.1 (a). The yarn center line equation in the local coordinate system can be stated as:

$$
\mathrm{y}^{\prime}=\mathrm{c}_{1}+\mathrm{c}_{2} \mathrm{x}^{\prime}+\mathrm{c}_{3}\left(\mathrm{x}^{\prime}\right)^{2}
$$


where $c_{1}, c_{2}, c_{3}$ can be calculated by the global coordinates of the two yarn end points and the midpoint of the yarn. The yarn center line equation in the global coordinate system can be obtained through coordinate transformation.

Let $a_{i}, b_{i}$ ( $i$ represents the yarn number) indicate the short axis and the long axis of the cross-section of each yarn, respectively. The ellipse parameters can be described as:

$$
\begin{cases}a_{i}=d / 2 & (i=1,2,3,4) \\ b_{i}=d /\left(2 \cos \gamma_{i}\right) & (i=1,2,3,4)\end{cases}
$$

where $\gamma_{i}$ is the angle between the tangent of the yarn center-line and the braid z-axis, which is continuously varying over the length of the yarn. The spatial geometry formulas of the yarns in the unit-cell are given as:

$$
\begin{cases}\mathrm{x}_{\mathrm{i}}=\mathrm{b}_{\mathrm{i}} \cos \left[\mathrm{s}_{\mathrm{i}}\right] \cos \left[\mathrm{t}_{\mathrm{i}}\right]-\mathrm{a}_{\mathrm{i}} \sin \left[\mathrm{s}_{\mathrm{i}}\right] \sin \left[\mathrm{t}_{\mathrm{i}}\right]+\mathrm{x}_{0 \mathrm{i}} & (\mathrm{i}=1,2,3,4) \\ \mathrm{y}_{\mathrm{i}}=\mathrm{b}_{\mathrm{i}} \sin \left[\mathrm{s}_{\mathrm{i}}\right] \cos \left[\mathrm{t}_{\mathrm{i}}\right]+\mathrm{a}_{\mathrm{i}} \cos \left[\mathrm{s}_{\mathrm{i}}\right] \sin \left[\mathrm{t}_{\mathrm{i}}\right]+\mathrm{y}_{0 \mathrm{i}} & (\mathrm{i}=1,2,3,4) \\ \mathrm{z}_{\mathrm{i}}=\mathrm{W}\left(\mathrm{s}_{\mathrm{i}} / \pi-1 / 4\right) \quad(\mathrm{i}=1,3), \quad \mathrm{z}_{\mathrm{i}}=\mathrm{W}\left(\mathrm{s}_{\mathrm{i}} / \pi+1 / 4\right) & (\mathrm{i}=2,4)\end{cases}
$$

where $\mathrm{x}_{0 \mathrm{i}}, \mathrm{y}_{0 \mathrm{i}}$ are the space point coordinates of the yarn center lines, which can be determined by Eq.(1), and $\mathrm{s}_{\mathrm{i}}, \mathrm{t}_{\mathrm{i}}$ are defined respectively as:

$$
\left\{\begin{array}{l}
\mathrm{s}_{\mathrm{i}} \in[\pi / 4,5 \pi / 4] \quad(\mathrm{i}=1,3), \quad \mathrm{s}_{\mathrm{i}} \in[-\pi / 4,3 \pi / 4] \quad(\mathrm{i}=2,4) \\
\mathrm{t}_{\mathrm{i}}=\varphi \pi / 180 \quad(\mathrm{i}=1,2,3,4)
\end{array}\right.
$$

\subsection{The finite multiphase element method}

On the basis of the cell-composition structure of 3D braided composites, a finite multiphase element method (FMEM) [12] has been proposed to predict the longitudinal tensile stress-strain relationships and the strength. The RVE is divided into a number of rectangular subcells as shown in Fig. 2(a). The yarn and matrix components do not need to be modeled discretely when the RVE is meshed. According to the material properties of the elements, three kinds of elements are obtained, as shown in Fig. 2(b). Let [ $\left.\mathrm{D}_{\mathrm{M}}\right],\left[\mathrm{D}_{\mathrm{Y}}\right]$ and $\left[D_{\text {Mix }}\right]$ denote the material property matrix of matrix element, yarn element and mixed element, respectively. The material property matrix $\left[\mathrm{D}_{\mathrm{Mix}}\right]$ varies with the coordinates of Gauss integration points. If the integration point is in the yarn volume, the material property matrix $\left[\mathrm{D}_{\mathrm{Y}}\right]$ is taken; otherwise the material property matrix $\left[\mathrm{D}_{\mathrm{M}}\right]$ is taken. According to the above helix geometry model and the design procedure of material property, a Fortran computer code is worked out to predict the longitudinal tensile stress-strain relationships and the strength of 3D braided composites accurately.

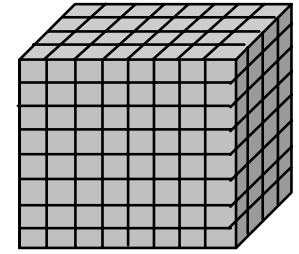

(a)

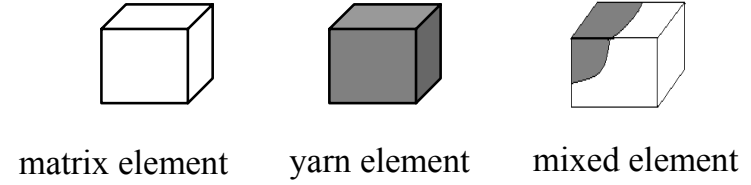

(b)

Fig.2 Discretization of a RVE: (a) RVE (b) three kinds of subcells 


\section{NUMERICAL CALCULATION AND DISCUSSIONS}

In this section, the longitudinal tensile stress-strain relationships and the strength of 3D braided composites under the tension loading have been predicted by FMEM based on the helix geometry model. In order to verify the reliability of these results, comparisons are presented between the numerical predictions and the available corresponding measurements [17]. All the analyses in the present study are done for the 3D four-directional braided composites by the four-step $1 \times 1$ rectangular braiding procedures, which consisted of $12 \mathrm{~K}$ T300 carbon yarns and TDE-85 epoxy resin. The mechanical properties of fiber and resin are given in Table 1. The stress-strain relationship and strength of 3D braided composites under tension loading can be computed as described in Ref. [13]. The Tsai-Wu and Von Mises criterion are used to predict the failure in the yarn and matrix, respectively.

Table 1 Mechanical properties of the component materials

\begin{tabular}{ccccccc}
\hline Materials & $\mathrm{E}_{11}(\mathrm{GPa})$ & $\mathrm{E}_{22}(\mathrm{GPa})$ & $\mathrm{G}_{12}(\mathrm{GPa})$ & $\mathrm{G}_{23}(\mathrm{GPa})$ & $\mu_{12}$ & $\mu \mathrm{m}$ \\
\hline Carbon fiber & 230 & 40 & 24 & 14.3 & 0.25 & \\
Epoxy resin & 3.5 & & & & & 0.35 \\
\hline
\end{tabular}

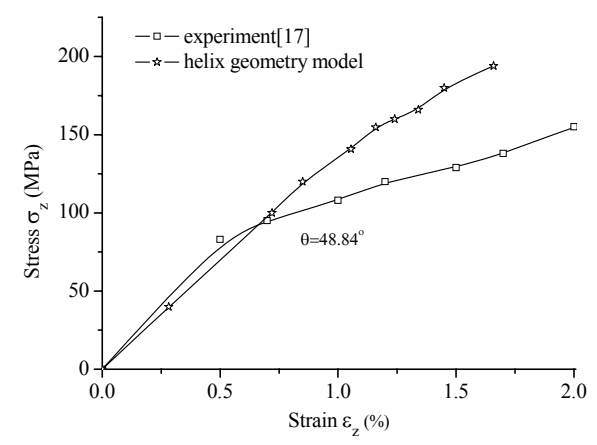

Fig. 3 Comparisons between the experimental and predicted values

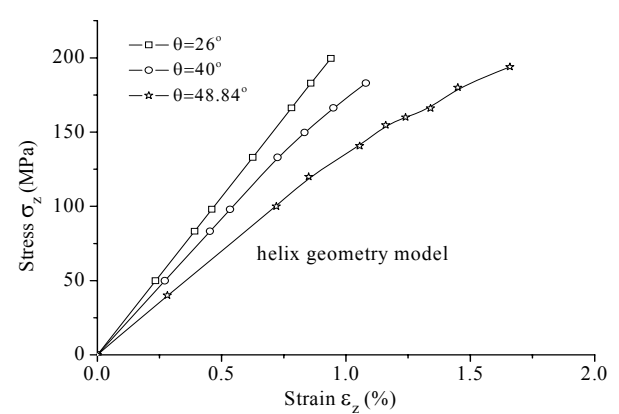

Fig. 4 Stress-strain behavior of 3D braided composites

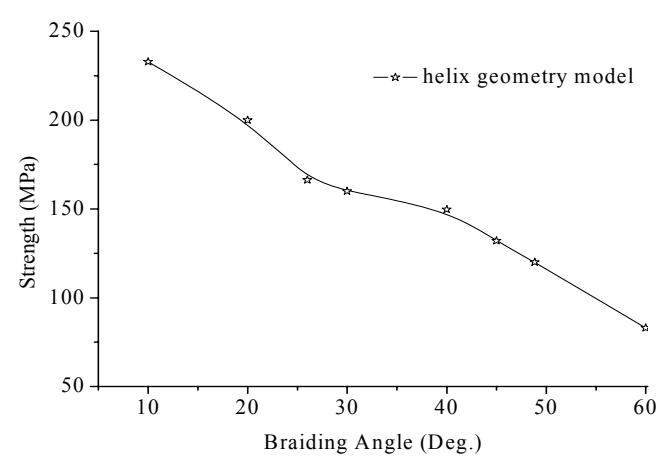

Fig. 5 Effect of braid angle on the tension strength

Fig. 3 presents the measured and predicted tensile stress-strain curve of 3D braided composites under tension loading, where $\theta$ is the surface yarn braiding angle. There is a good 
Based on the Helix Geometry Model

agreement between the measured and predicted tensile stress-strain in the initial elastic region. During the latter stage, the tensile stress-strain curve crosses the corresponding experimental curve and the displacement measured experimentally is higher than the theoretical prediction. The primary reason for the latter stage is that the experimental results under the influence of the equipment and surrounding environment, while the numerical calculation is assumed to progress under ideal conditions. Furthermore, there is not perfect adhesion between the matrix and the fibres in the $3 \mathrm{D}$ braided composites.

Fig. 4 shows the effect of the braiding angle on the longitudinal tensile stress-strain curve of 3D braided composites. When the braiding angle is smaller, the longitudinal tensile stress-strain relationships present linearity. But with the braiding angle increases, the longitudinal tensile stress-strain relationships demonstrate nonlinearity.

The variation of the predicted longitudinal tensile strength of 3D braided composites with the braiding angle is shown in Fig.5. It can be seen that the longitudinal tensile strength decreases with increasing braiding angle. The influence of braiding angle on the longitudinal tensile strength is remarkable and the corresponding strength has a reduction of $64.3 \%$ when the braiding angle varies from $10^{\circ}$ to $60^{\circ}$. Under tension loading, the tension failure initiates in the matrix elements at around $166.3 \mathrm{MPa}\left(\theta=26^{\circ}\right), 149.7 \mathrm{MPa}\left(\theta=40^{\circ}\right)$, and $120 \mathrm{MPa}$ $\left(\theta=48.84^{\circ}\right)$, respectively.

\section{CONCLUSION}

This paper develops corresponding Fortran computer codes based on the helix geometry model, through which the longitudinal tensile stress-strain relationships and the strength of 3D braided composites under the tension loading have been predicted.

(i) The helix geometry model findings are compared to reported experimental findings in the literature and excellent results are obtained.

(ii) The braiding angle has a significant influence on the strength of $3 \mathrm{D}$ braided composites under tension loading.

(iii) The tension failure of 3D braided composites initiates in the matrix elements under tension loading.

(iv) Future work will focus on the fatigue damage analysis of 3D braided composites subjected to tension-tension fatigue loading.

\section{ACKNOWLEDGEMENTS}

The authors would like to thank the National Natural Science Foundation of China (10772064, 10972070), the Program for New Century Excellent Talents in University (NCET-07-0247), the National Key Program for Developing Basic Research of China (2009CB626609) and Excellent Youth Foundation of Heilongjiang Scientific Committee (JC200910).

\section{REFERENCES}

1. T. W. Chou and F. K. Ko, Textile Structural Composites, Elsevier Science Publishers, Amsterdam, 1989.

2. D. W. Whyte, Ph.D. thesis, Drexel University, Philadelphia, PA, 1986. 
3. C. L. Ma, J. M. Yang, T. W. Chou, Elastic stiffness of three-dimensional braided textile structural composites, Composite Materials: Testing and Design, Seventh Conference, 404-421, 1984.

4. J. M. Yang, C. L. Ma, T. W. Chou, Fiber inclination model of three-dimensional textile structural composites, Journal of Composite Materials 20, 472-483, 1986.

5. J. H. Byun, G. W. Du, T. W. Chou, Analysis and modeling of three dimensional textile structural composites, High-Tech Fibrous Materials (ACS Symposium Series 457), 22-33, 1991.

6. Z. G. Huang, A braiding model prediction of the ultimate strength of composite laminates subject to biaxial loads, Composites Science and Technology 64, 395-448, 2004.

7. D. S. Li, Z. X. Lu, W. S. Lu, Theoretical prediction of stiffness and strength of threedimensional and four-directional braided composites, Applied Mathematics and Mechanics 29, 163-170, 2008.

8. H. Y. Sun, X. Qiao, Prediction of the mechanical properties of three dimensionally braided composites, Composites Science and Technology 57, 623-629, 1997.

9. Y. Q. Wang, A. S. D. Wang, Microstructure/property relationships in threedimensionally braided fiber composites, Composites Science and Technology 53, 213 222, 1995.

10. J. D. Whitcomb, K. Woo, Macro finite element for analysis of textile composites, Journal of Composite Materials 28, 607-618, 1994.

11. T. Zeng, L. Z. Wu, L. C. Guo, Mechanical analysis of 3D braided composites: a finite element model, Composite Structures 64, 399-404, 2004.

12. T. Zeng, L. Z. Wu, L. C. Guo, A finite element model for failure analysis of 3D braided composites, Materials Science and Engineering 366, 144-151, 2004.

13. T. Zeng, D. N. Fang, L. Ma, L. C. Guo, Predicting the nonlinear response and failure of 3D braided composites, Materials Letters 58, 3237-3241, 2004.

14. B. H. Gu. Prediction of the uniaxial tensile curve of 4-step 3-dimensional braided perform, Composite Structures 64, 235-241, 2004.

15. X. G. Yu, J. Z. Cui, The prediction on mechanical properties of 4-step braided composites via two-scale method, Composites Science and Technology 67, 471-480, 2007.

16. S. R. Kalidindi and E. Franco. Numerical evaluation of isostrain and weighted- average models for elastic moduli of three-dimensional composites. Composites Science and Technology 57, 293-305, 1997.

17. B. J. Pang, Ph.D. thesis, Harbin Institute of Technology, March 1997. 